\title{
Ceria - Fundamentals and Applications in Different Fields of Gas Sensors
}

\author{
Noriya Izu \\ National Institute of Advanced Industrial Science and Technology (AIST) \\ 2266-98 Anagahora, Shimo-Shidami, Moriyama-ku, Nagoya 463-8560 Japan \\ n-izu@aist.go.jp
}

\begin{abstract}
Ceria, cerium oxide, is attractive to many applications. This paper focuses on gas sensors using ceria. Ceria can change its oxidation state from $\mathrm{Ce}^{3+}$ to $\mathrm{Ce}^{4+}$ and vice versa, and the resistance of ceria changes with the oxidation state of cerium ion at temperatures higher than $300^{\circ} \mathrm{C}$. In this paper, three kinds of resistive type sensors using ceria are introduced. First, oxygen sensors with fast response properties or temperature independent signal are described. Next, carbon monoxide sensors which have fast response properties or are made from nanoparticles with very unique structures are explained. In the last part, odor sensors which can measure very low concentrations of $\mathrm{H}_{2} \mathrm{~S}$ are also introduced.
\end{abstract}

Key words: cerium oxide, resistive type, gas sensor, oxygen, carbon monoxide, odor

\section{Introduction}

Well-known semiconductor gas sensors, which are the so-called "surface type", operate on the following principle: Flammable gases react with oxygen adsorbed on the surface of grains of the semiconductors such as tin dioxide, with the electrical resistance dropping due to disappearance of the depletion layer near the grain surface [1]. On the other hand, recently gas sensors that utilize changes in physical properties throughout the entire grains, which are the so-called "non-surface type", have attracted considerable attention because they are expected to have good stability and reproducibility [1]. We focus on cerium oxide, ceria, as a sensing material of "non-surface type".

Cerium oxide itself exhibits a range of useful functions, including high oxygen storage capacity [2] and high diffusion coefficient for the oxide ion [3], and is used in a range of applications; as a promoter in three-way catalysts, oxide ion conductors, and resistive oxygen gas sensors. A number of devices incorporating cerium oxide are now in practical use. Cerium oxide can change its oxidation state from $\mathrm{Ce}^{3+}$ to $\mathrm{Ce}^{4+}$ and vice versa [2]. This property makes it possible to use cerium oxide in wide range applications.

Although there are several reports concerning sensors using $\mathrm{SnO}_{2}$ or $\mathrm{ZnO}$ doped with cerium oxide [4], some sensors using cerium oxide as a primary phase are introduced in this paper.

\section{Principle of Resistive Type Ceria Gas \\ Sensor}

Defect reaction is as follows:

$2 \mathrm{Ce}_{\mathrm{Ce}}{ }^{\mathrm{x}}+\mathrm{O}_{\mathrm{O}}{ }^{\mathrm{x}}=2 \mathrm{Ce}_{\mathrm{Ce}}{ }^{\prime}+\mathrm{V}_{\mathrm{o}}{ }^{\prime \prime}+1 / 2 \mathrm{O}_{2}$

When oxygen concentration decreases, the equilibrium shifts to right and $\mathrm{Ce}_{\mathrm{Ce}}{ }^{\prime}$ and $\mathrm{V}_{\mathrm{O}}$ increase on the surface of cerium oxide. Afterwards $\mathrm{Ce}_{\mathrm{Ce}}$ ' and $\mathrm{V}_{\mathrm{O}}$ " diffuse to inside. Finally the equilibrium is achieved. Since the charge carrier is $\mathrm{Ce}_{\mathrm{Ce}}$ ' in cerium oxide, the electrical conductivity of cerium oxide increases. Here the diffusion coefficient of $\mathrm{V}_{\mathrm{O}}$ is much smaller than that of $\mathrm{Ce}_{\mathrm{Ce}}$ '. Therefore, the surface reaction (Eq. (1)) and the $\mathrm{V}_{\mathrm{O}}$ diffusion are very important when we consider the rate-limiting step of the sensor response (Fig. 1).

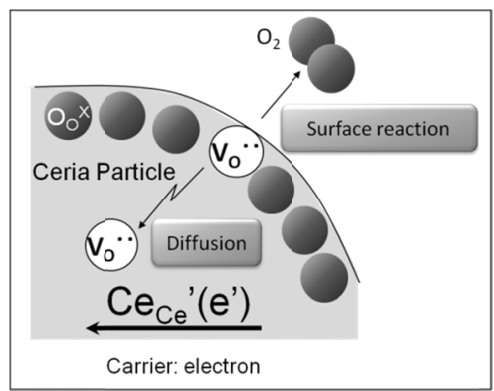

Fig. 1. Reaction near the surface of ceria. 


\section{Oxygen Sensor}

Beie and Gnörich [5] investigated the oxygen gas sensing properties of thick- and thin-films of cerium oxide. In the case of thick films, their response time was in the range of some minutes. In the case of thin films, the response time was assumed to be $10 \mathrm{~ms}$, although no data was shown. We, therefore, started the research and development of fast response oxygen sensors using cerium oxide.

In order to shorten the response time of sensors, we prepared cerium oxide thick films based on nanoparticles. The nanoparticles were made by a modified precipitation method. The particle size of the thick film prepared from $10 \mathrm{~mol} \% \mathrm{Zr}$-doped ceria nanoparticles was about $90 \mathrm{~nm}$ after a firing process at $1100^{\circ} \mathrm{C}$. The $90 \%$ response time of the sensor of the ceria thick film was 4 to $27 \mathrm{~ms}$ at $700{ }^{\circ} \mathrm{C}$, when the oxygen partial pressure was suddenly changed between 64 and $24 \mathrm{kPa}$.

By a pressure modulation method, it revealed that the response of the thick film with nanometer particle size was strongly controlled by diffusion of $\mathrm{V}_{\mathrm{O}}{ }^{\prime}[6]$.

$\mathrm{SrTi}_{1-\mathrm{x}} \mathrm{FeO}_{3}$ is well known as a $p$-type oxygen sensing material whose resistance is independent of temperature [7]. In the case of $n$-type semiconducting materials, however, no mechanism is known to reduce the temperature dependence of their resistance materialintrinsically. Therefore, a second material that compensates the temperature dependence is required.

It is explained how to prevent the temperature dependence of an $n$-type oxygen sensor utilizing a temperature compensating material (TCM) in principle. When a constant voltage, $V$, is applied to the serial circuit of TCM and gas sensitive material, the potential difference of the sensing material, $E_{\text {output }}$, can be expressed as follows:

$$
E_{\text {ouput }}=\frac{r_{0}}{\left(r_{0}+r_{\mathrm{t}}\right)} \times V=\frac{r_{0}^{\circ} \times p \mathrm{O}_{2}^{1 / n} \times \exp \left(\frac{E_{\mathrm{o}}}{k T}\right)}{r_{0}^{\circ} \times p \mathrm{O}_{2}^{1 / n} \times \exp \left(\frac{E_{\mathrm{o}}}{k T}\right)+r_{\mathrm{t}}^{0} \times \exp \left(\frac{E_{\mathrm{t}}}{k T}\right)} \times V
$$

where $r_{0}^{\circ}$ and $r_{\mathrm{t}}{ }^{\circ}$ are the inherent constant values of sensing material and TCM, respectively, which are independent of oxygen partial pressure and temperature, $p \mathrm{O}_{2}$ is the oxygen partial pressure, $n$ is a parameter indicating oxygen partial pressure dependence (normally 4 to 6 ), $E_{\mathrm{o}}$ and $E_{\mathrm{t}}$ are the activation energies of the conductivity of the sensing material and the TCM, respectively, and $k$ is Boltzmann's constant. If $E_{\mathrm{o}}$ is the same as $E_{\mathrm{t}}$, then Equation (2) simplifies to
$E_{\text {output }}=\frac{r_{\mathrm{o}}^{\circ} \times p \mathrm{O}_{2}{ }^{1 / n}}{r_{0}^{O} \times p \mathrm{O}_{2}{ }^{1 / n}+r_{\mathrm{t}}^{O}} \times V$

In Eq. (3), the temperature dependent term disappears. In other words, the sensor output is independent of temperature.

Typical results are shown here. In Ref. [8], TCMs were investigated for a resistive oxygen sensor using $\mathrm{Ce}_{0.9} \mathrm{Zr}_{0.1} \mathrm{O}_{2} \quad(\mathrm{CeZr} 10)$ as a sensing material for lean-burn engines. The temperature compensating material should have the same temperature dependence of resistance as the sensor material and a resistivity that is independent of the oxygen partial pressure. As a result of an yttria concentration optimization in the TCM $\left(\mathrm{CeO}_{2}\right.$ $\mathrm{Y}_{2} \mathrm{O}_{3}$ ), it has been revealed that CeY50 $\left(\mathrm{Ce}_{0.5} \mathrm{Y}_{0.5} \mathrm{O}_{2-\delta}\right)$ has the same activation energy of resistance as the oxygen sensitive composition, CeZr10, but with a $\mathrm{pO}_{2}$ independent resistivity. The output of the sensor element that comprises CeZr10 and $\mathrm{CeY} 50$ as sensor and temperature compensating materials was approximately independent of temperature in a wide range from $500{ }^{\circ} \mathrm{C}$ to $800{ }^{\circ} \mathrm{C}$.

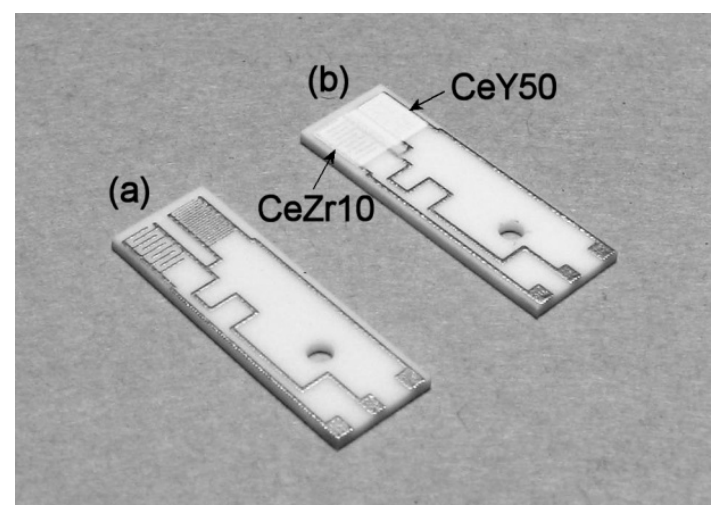

Fig. 2. Image of the sensing elements. (a) the substrate with electrodes, (b) the element with $\mathrm{Ce}_{0.9} \mathrm{Zr}_{0.1} \mathrm{O}_{2}$ (CeZr10) and CeY50 (Ce $\left.\mathrm{Ce}_{0.5} \mathrm{Y}_{0.5} \mathrm{O}_{2-\delta}\right)$. From [8].

\section{CO Sensor}

There are some reports concerning sensors using cerium oxide for detecting $\mathrm{CO}$ [9]. For carbon monoxide (CO) sensor, it is necessary to achieve fast-response, because it is said that people die in 1 to $3 \mathrm{~min}$ after the $\mathrm{CO}$ concentration in air becomes $1.28 \%$. We focus on response time of $\mathrm{CO}$ sensor using cerium oxide [10].

The resistance decreased markedly as soon as air with $\mathrm{CO}$ was introduced at $450^{\circ} \mathrm{C}$. The response time for changes of $90 \%$ was $2.0 \mathrm{~s}$ at $450^{\circ} \mathrm{C}$ in the case of the thick film with a particle size of $58 \mathrm{~nm}$. Therefore, it became clear that 
the thick film responded very quickly to $\mathrm{CO}$ introduction.

As mentioned above, the thick film using cerium oxide responded to not only $\mathrm{CO}$ but also oxygen. In order to use the cerium oxide thick film as a $\mathrm{CO}$ sensor, the oxygen dependency should be eliminated. To eliminate the oxygen dependency of sensing signal, we prepared the following sensing element, a serial circuit of a cerium oxide thick film with a combustion catalyst layer and a cerium oxide thick film without the catalyst layer. When the constant voltage is applied to the serial circuit, the potential difference of the thick film with or without the catalyst is obtained as a sensing signal. If the combustion catalyst layer oxidized only $\mathrm{CO}$, we can obtain not only oxygen independency but also selectivity for other gases. It was demonstrated that the sensor signal was almost independent of oxygen concentration and that the sensor element showed low response for combustible gases such as methane, ethane, propane, ethylene and $\mathrm{H}_{2}$ at $450^{\circ} \mathrm{C}$.

It is very important for good sensitivity to control the structure of sensing material. It is expected that if sensing material has macro porous structure that consist of clusters, it would show good sensitivity. Recently we have developed very unique nanoparticles which have a monodispersed cluster structure (Fig. 3). Therefore, ceria thick films from these unique clustered nanoparticles were fabricated in order to improve the CO sensitivity [11].

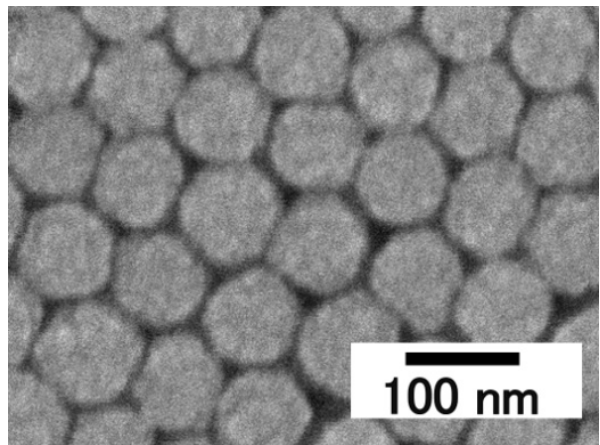

Fig. 3. Image of nanoparticles with a monodispersed cluster structure. From [12].

The particle size of the thick film prepared from the monodispersed nanoparticles which have very narrow size distribution was about $120 \mathrm{~nm}$. The sensitivity to $\mathrm{CO}$ gas of the sensor prepared from the nanoparticles of polyol method was larger than that of modified precipitation method. Furthermore, by adding Au nanoparticles on the thick film, the sensitivity to $\mathrm{CO}$ gas increased. From these results, it is expected that the unique cerium oxide nanoparticles have potential to be applied for various gas sensors.

\section{Odor Sensor [13]}

Next, we analyzed the sensitivity of the cerium oxide thick films for other gases such as $\mathrm{H}_{2} \mathrm{~S}$, $\left(\mathrm{CH}_{3}\right)_{2} \mathrm{CHO}, \mathrm{CH}_{3} \mathrm{COOH}, \mathrm{C}_{6} \mathrm{H}_{5} \mathrm{CH}_{3}$ and so on. The sensitivity for $\mathrm{H}_{2} \mathrm{~S}$ at $500^{\circ} \mathrm{C}$ is the largest among the other gases chosen in this study. For example, the ratio of resistance in air to that in $500 \mathrm{ppb}$ (part per billion) $\mathrm{H}_{2} \mathrm{~S}$ is approximately 2. $\mathrm{H}_{2} \mathrm{~S}$ is one of odor components in human breath. One of the other odor components is $\mathrm{CH}_{3} \mathrm{SH}$. We investigated the sensitivity of the cerium oxide thick film for $\mathrm{CH}_{3} \mathrm{SH}$. The sensitivity of $\mathrm{CH}_{3} \mathrm{SH}$ is almost the same as that of $\mathrm{H}_{2} \mathrm{~S}$.

We also investigated response time. The response times for $\mathrm{H}_{2} \mathrm{~S}$ and $\mathrm{CH}_{3} \mathrm{SH}$ are less than $10 \mathrm{~s}$ and the recovery times for them are less than $60 \mathrm{~s}$. These response times and recovery times of the cerium oxide thick film are much shorter than those of the $\mathrm{ZnO}$ thick film, which have been already commercialized as an odor sensor. It is also clarified that the sensor signal is independent of atmospheric temperature and humidity and that the resistance of the whole grain of cerium oxide changes when $\mathrm{H}_{2} \mathrm{~S}$ comes to the surface of cerium oxide grain. Recently the odor sensor equipments developed by the collaboration partner and our group have been brought to market.

\section{Summary}

Here the sensors using cerium oxide were introduced. The oxygen sensors using cerium oxide thick films with a particle size of $\sim 100 \mathrm{~nm}$ showed very fast response with a $90 \%$ response time of $\sim 10 \mathrm{~ms}$ and the late-limiting step of the oxygen sensors was clarified to be oxygen vacancy diffusion. The CO sensors using cerium oxide thick films with a particle size of $\sim 100 \mathrm{~nm}$ also showed fast response, and the method to obtain the selectivity of $\mathrm{CO}$ gas was invented. When the monodispersed clustered nanoparticles were used as a source material for the thick film, the sensor response improved. Furthermore, the cerium thick films showed good sensitivity to odor components such as $\mathrm{H}_{2} \mathrm{~S}$ and $\mathrm{CH}_{3} \mathrm{SH}$, and the odor sensor equipments using the cerium oxide thick film have been brought to market recently.

\section{Acknowledgements}

This paper includes results conducted by $\mathrm{Dr}$. N. Murayama, Dr. I. Matsubara, Dr. W. Shin, and Dr. T. Itoh in AIST, Mr. S. Nakamura and Mr. K. 
Suzuki in New Cosmos Electric Co., Ltd. I would like to acknowledge them gratefully.

\section{References}

[1] N. Murayama, J. Ceram. Soc. Jpn. 116, 1167 (2008).

[2] H. C. Yao, Y. F. Yu Yao, J. Catal. 86, 254 (1984).

[3] F. Millot, P. De Mierry, J. Phys. Chem. Solids 46, 797 (1985).

[4] e.g. Z. Jiang, Z. Guo, B. Sun, Y. Jia, M. Li, J. Liu, Sens. Actuators B 145, 667 (2010).

[5] H.-J. Beie, A. Gnörich, Sens. Actuators B 4, 393 (1991).

[6] N. Izu, T. Itoh, W. Shin, I. Matsubara, Sens. Actuators B 130, 466 (2008).

[7] R. Moos, W. Menesklou, H.-J. Schreiner, K.H. Härdtl, Sens. Actuators B 67, 178 (2000)

[8] N. Izu, S. Nishizaki, W. Shin, T. Itoh, M. NIshibori, I. Matsubara, Sensors 9, 8884 (2009).

[9] e.g. T. S. Stefanik, H. L. Tuller, J. Electroceram. 13, 771 (2004).

[10] N. Izu, S. Nishizaki, T. Itoh, M. NIshibori, W. Shin, I. Matsubara, Sens. Actuators B 364, 136 (2009).

[11] N. Izu, I. Matsubara, T. Itoh, W. Shin, M. Nlshibori, Japanese Unexamined Patent Application Publication No. 2009-175131 (2009).

[12] http://www.aist.go.jp/aist_j/openlab/2011/program /contents/pdf/p202_p288.pdf pp.237.

[13] S. Nakamura, K. Suzuki, N. Izu, I. Matsubara, Japanese Unexamined Patent Application Publication No. 2010-2335 (2010). 